\title{
APLICAÇÃO DA TÉCNICA DE SELEÇÃO VISUAL: ESTUDO DE CASO EM RESIDENCIAL DE IDOSOS NA PARAÍBA
}

\section{APPLICATION OF THE VISUAL CUES TECHNIQUE: CASE STUDY ON RESIDENTIAL HOME OF ELDERLY PEOPLE IN PARAÍBA}

\author{
Elzani Sobral ${ }^{1}$, M.Sc. \\ Marie Paiva ${ }^{2}$, M.Sc. \\ Vilma Vllarouco ${ }^{3}$, D.Sc. \\ (1) Universidade Federal de Pernambuco (UFPE) \\ e-mail:sobral.rafaela@hotmail.com \\ (2) Universidade Federal de Pernambuco (UFPE) \\ e-mail: mariem.paiva@gmail.com \\ (3) Universidade Federal de Pernambuco (UFPE) \\ e-mail: villarouco@hotmail.com.br
}

Palavras-chave: Idosos, Relação pessoa-ambiente, Seleção visual

\begin{abstract}
A fase da velhice incorpora novos hábitos e necessidades específicas, além de uma nova forma de perceber e enxergar o mundo. As experiências adquiridas ao longo de suas vidas e o declínio físico e cognitivo influenciam o modo de viver dos idosos, refletindo diretamente sobre seus anseios. Nesse contexto, entender de que modo os idosos percebem os espaços torna-se fundamental para a relação pessoa-ambiente e seus efeitos no comportamento humano. Assim, o presente artigo tem como objetivo identificar as preferências e desejos dos idosos quanto ao ambiente físico através da técnica de Seleção Visual.
\end{abstract}

\section{Keywords: Elderly, person-environment relation, Visual Cues}

The senior age phase incorporates new habits and specific needs, as well as a new way of perceiving and seeing the world. The experiences acquired throughout their lives and the physical and cognitive decline influence the way of life of the elderly, reflecting directly on their desires. In this context, understanding how the elderly perceive the spaces becomes fundamental for the person-environment relation and its effects on human behavior. Thus, the present article aims to identify the preferences and desires of the elderly regarding the physical environment through the Visual Cues technique. 


\section{$16^{\circ}$ \\ ERGODESIGN USIHC CINAHPA}

\section{Introdução}

Relativamente recente no mundo contemporâneo, apenas no início desse século a Ergonomia procurou empregar conhecimentos ao interior e construções [VERONESI, 2008]. Mais precisamente na área do ambiente construído objetivando a interação do indivíduo com o meio, considerando aspectos sociais, psicológicos, organizacionais e culturais.

Outro olhar relevante da relação homem-ambiente construído envolve aspectos referentes ao sentimento que o usuário tem através da experimentação do ambiente. Dessa forma, estudos sobre os ambientes habitados por pessoas idosas têm se destacado, não só pela latência do tema que hoje permeia diversos segmentos da pesquisa científica, mas pela diversidade de ramificações que vem se apresentando.

Nesse cenário, o presente artigo apresenta a percepção do usuário idoso relacionada aos espaços de moradia por meio da aplicação da técnica de Seleção Visual [SANOFF, 2001].

\subsection{Adequação de ambientes e percepção}

Saber de que modo os usuários experimentam e percebem os ambientes, entendendo sua influência no comportamento humano e como este intervém no ambiente servirá de subsídio para adequações espaciais e proposições de projetação para espaços adequados ergonomicamente.

A percepção do ambiente ocorre simultaneamente de modo consciente e inconsciente, através de estímulos, onde a mente seletiva atua na captura desses estímulos gerando uma resposta comportamental [PINHEIRO \& ELALI, 2011; DEL RIO, 1999]. Como resposta à avaliação sensorial imediata tem-se o julgamento, ou entendimento do ambiente gerado através de imagens, permeado por modelos mentais decorrentes de experiência prévia, significados e valores [GJERD, 2010]. $16^{\circ}$ Ergodesign - Congresso Internacional de Ergonomia e Usabilidade de Interfaces Humano Tecnológica: Produto, Informações Ambientes Construídos e Transporte

$16^{\circ}$ USIHC - Congresso Internacional de Ergonomia e Usabilidade de Interfaces Humano Computador

CINAHPA | 2017 - Congresso Internacional de Ambientes Hipermídia para Aprendizagem.

Para Nathan et al.[2014] o entendimento da percepção do usuário sobre seu ambiente guarda relevância tão ou maior que o conhecimento dos aspectos formais do espaço edificado. Assim, o conhecimento da influência recíproca do sistema usuário-ambiente, bem como das sensações decorrentes da percepção ambiental é de grande relevância, impactando diretamente nas ações comportamentais humanas vinculadas ao ambiente [SOBRAL, PAIVA \& VILLAROUCO, 2016].

\subsection{Relação usuário-ambiente e moradia}

Considerando-se que a adequação ergonômica de um ambiente deve atender e entender também a percepção dos seus usuários, as metodologias e técnicas aplicadas preveem a utilização da percepção ambiental como suporte teórico e ferramental para esta necessidade.

A percepção varia de acordo com a composição dos grupos de pessoas - crianças, adultos e idosos, onde as informações são assimiladas através do repertório próprio de cada um deles, bem como da maturidade relacionada às suas individualidades [PAIVA, SOBRAL \& VILLAROUCO, 2016].

Relativamente ao usuário idoso, a percepção tornase mais complexa e delicada devido à presença do declínio cognitivo associado ao envelhecimento que pode interferir nos resultados mascarando o verdadeiro julgamento espacial. O entendimento das demandas e anseios dos idosos quanto ao ambiente é permeado por vezes por carências e pouca presença de horizontes, o que contribui para aceitação da realidade vivenciada.

\subsection{Contextualizando a pesquisa}

O objeto de estudo foi o residencial Cidade Madura, localizado na cidade de João Pessoa, na Paraíba, onde foram construídas 40 casas visando atender idosos com 60 anos ou mais, residentes na cidade, de baixa renda financeira e que apresentem capacidade de realizar suas atividades diárias sem auxílios de terceiros.

Todas as residências são iguais e dispõem de
Realização:

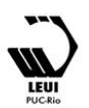




\section{$16^{\circ}$ \\ ERGODESIGN USIHC CINAHPA}

terraço, sala de jantar e estar, cozinha, área de serviço, quarto e banheiro acessível. O condomínio tem possui área de lazer, academia, redário (local para colocar redes), horta comunitária, salão de festa, sala para administração, centro médico e portaria. Todo o residencial foi projetado considerando aspectos acessíveis que possibilitam um melhor uso dos espaços e garantindo segurança aos idosos.

\section{Procedimentos Metodológicos}

Para essa pesquisa foi utilizada a técnica de Seleção Visual proposta por Henry Sanoff [2000; 2001] que permite escolher previamente um grupo de imagens relacionadas aos ambientes utilizados pelos usuários. A técnica foi aplicada a uma amostra aleatória e composta de 20 idosos, de ambos os sexos. As imagens apresentadas foram escolhidas previamente e obtidas por meio de pesquisas de ambientes projetados para idosos bem como ambientes que não possuíam esse foco. Sendo assim, essas imagens foram misturadas a fim de verificar se características presentes em projetos voltados para idosos seriam percebidas e relevantes nas escolhas dos pesquisados.

O fator socioeconômico e cultural também foi considerado na seleção das imagens que fizeram parte da pesquisa. Além de imagens de ambientes próximos à realidade dos usuários também foi inserido na pesquisa fotos de ambientes acima do padrão socioeconômico dos idosos a fim de verificar o desejo dos pesquisados.

Durante a aplicação da ferramenta, foi solicitado ao pesquisado que apontasse os aspectos positivos e negativos de cada ambiente das imagens, não sendo elaborado um questionário auxiliar da Seleção Visual. Essa adaptação da ferramenta foi estabelecida para permitir a livre expressão do idoso. Após a ferramenta ter sido aplicada, todos os comentários obtidos foram categorizados de acordo com aspectos expressados pelos usuários, gerando gráficos que indicaram a recorrência dessas características. $16^{\circ}$ Ergodesign - Congresso Internacional de Ergonomia e Usabilidade de Interfaces Humano Tecnológica: Produto, Informações Ambientes Construídos e Transporte

$16^{\circ}$ USIHC - Congresso Internacional de Ergonomia e Usabilidade de Interfaces Humano Computador

CINAHPA | 2017 - Congresso Internacional de Ambientes Hipermídia para Aprendizagem.

\section{Resultados e Discussões}

Nesta sessão apenas serão apresentadas imagens que apresentaram comentários e dados mais significativos de acordo com respostas dos pesquisados.

Ao analisar os comentários dos participantes da pesquisa em relação às salas, um aspecto considerado importante na aceitação do ambiente foi a aproximação com a realidade socieconômicados idosos. As salas que apresentavam características semelhantes às deles [Figura 2] foram bem mais aceitas quando comparada a outras que foram categorizadas como "luxuosas".

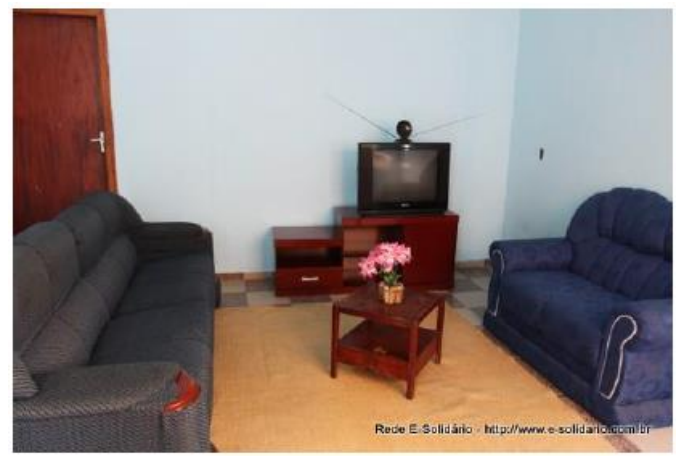

Figura 2: Sala com proximidade socioeconômica Fonte: http://www.esolidario.com.br/blog/2012/08/larde-sarepta-cuidando-com-muito-carinho-dos-idosos/

Mesmo com esse aspecto sendo relavante nas considerações dos usuários, a imagem que obteve maior relevância foi aquela que eles consideraram a mais "bonita" [Figura 3].

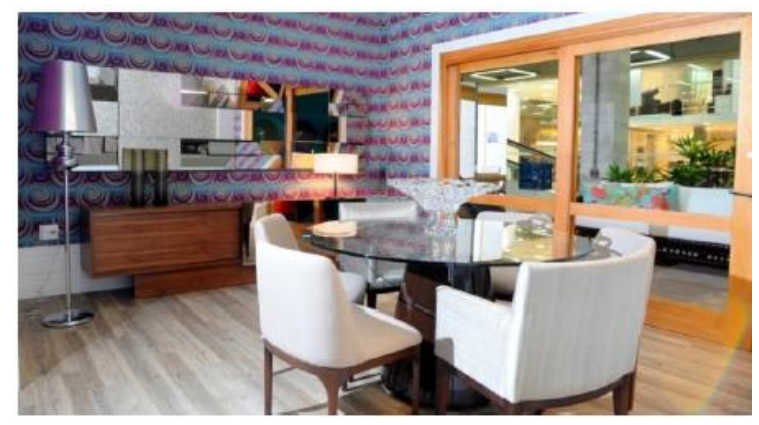

Figura 3: Sala considerada com melhor estética Fonte: http://casa.abril.com.br/profissionais/confira-
Realização:

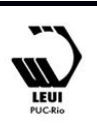




\section{$16^{\circ}$ \\ ERGODESIGN USIHC CINAHPA}

ambientes-adaptados-para-idosos-ou-pessoas-comdeficiencia/

Este ambiente, comparado aos demais foi o que apresentou maior índice de comentários positivos. Ao analisar e contrastar com os comentários acerca das salas apresentadas, aspectos como estética e espaço amplo foram os mais citados nas respostas. Isso enfatiza a importância desses atributos em ambientes voltados para o público idoso. Mesmo eles possuindo consciência da sua realidade econômica, isso não foi impedimento quanto ao desejo apresentado pelos pesquisados em terem uma sala com essas características.

Em relação aos quartos, um dos aspectos presentes nos relatos dos pesquisados é a presença de mobiliários adequados, fazendo com que os ambientes que continham esse atributo fossem os mais aceitos. O Quarto apontado como o mais "bonito" [Figura 4] foi o que apresenta em sua configuração mobiliários de apoio, espaço amplo e boa iluminação, segundo os idosos.

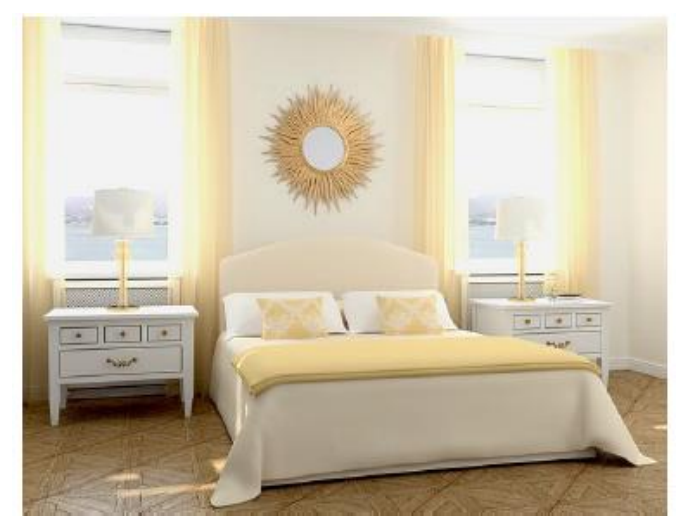

Figura 4: Quarto com melhor configuração

Fonte: http://vidaeestilo.terra.com.br/casa-edecoracao/confira-15-dicas-fundamentais-para-decorarcasas-de

idosos,e518e4ddfce27310VgnCLD100000bbcceb0aRC RD.html

Os quartos que apresentaram alto índice de rejeição por parte dos pesquisados, foram aqueles que tinham sua configuração associada a um quarto de hospital ou uma ILPI [instituição de longa permanência], onde a presença de uma cadeira de rodas foi notada com desconforto $16^{\circ}$ Ergodesign - Congresso Internacional de Ergonomia e Usabilidade de Interfaces Humano Tecnológica: Produto, Informações Ambientes Construídos e Transporte

$16^{\circ}$ USIHC - Congresso Internacional de Ergonomia e Usabilidade de Interfaces Humano Computador

CINAHPA | 2017 - Congresso Internacional de Ambientes Hipermídia para Aprendizagem.
[Figura 5].

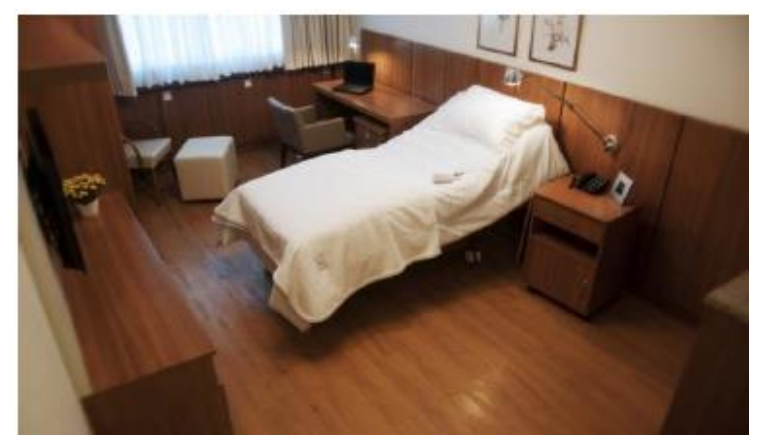

Figura 5: Quarto maior rejeição

Fonte: http://portalamigodoidoso.com.br/bem-estar-doidoso-2/

Características como amplo dimensionamento, boa iluminação, mobiliário adequado e estética foram os aspectos considerados favoráveis para esse tipo de ambiente.

Para os banheiros, a proximidade com a realidade socioeconômica foi um aspecto decisivo apontado pelos idosos. Tal característica influenciou diretamente a escolha da imagem pela maioria dos idosos [Figura 6].

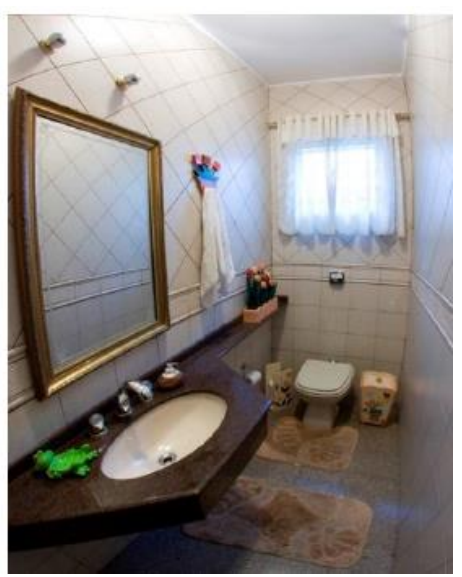

Figura 6: Banheiro de que mais se gostou Fonte:

https://vendocasaemcuritiba.wordpress.com/2010/06/27/ banheiro-visita-piso-inferior/

Porém, o banheiro que considerado mais bonito foi o que apresenta características semelhantes ao contido na casa dos idosos, apresentando barras de apoio [Figura7].
Realização:

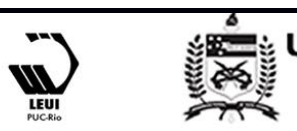




\section{$16^{\circ}$ \\ ERGODESIGN USIHC CINAHPA}

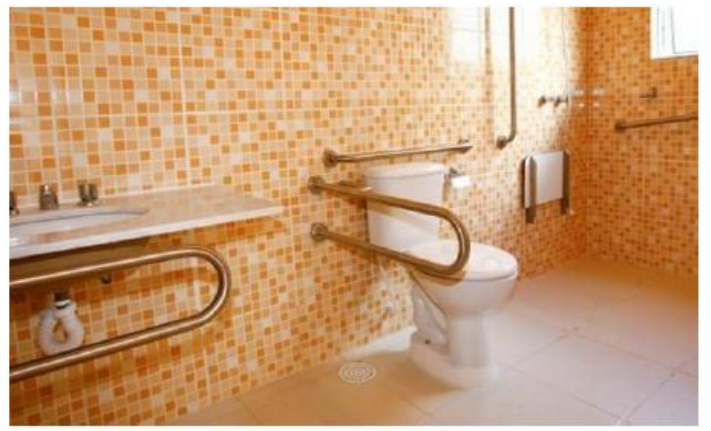

Figura 7: Banheiro considerado mais bonito Fonte:http://www.sempretops.com/informacao/adaptaco es-para-casas-com-idosos/

Assim, foi verificado que relativamente aos banheiros, o reconhecimento da realidade prevaleceu em relação aos valores estéticos.

Já em relação às cozinhas, a que mais permitiu a identificação com o próprio ambiente pode ser vista na Figura 9, abaixo, onde a presença de uma janela foi sinalizada como um atributo positivo, como pode ser notado nas seguintes falas: "Isso é uma janela? É, pra entrar um arzinho tá boa toda; "Essa é melhor. Tudo que tiver janela é melhor"; "é quase parecida com a daqui".

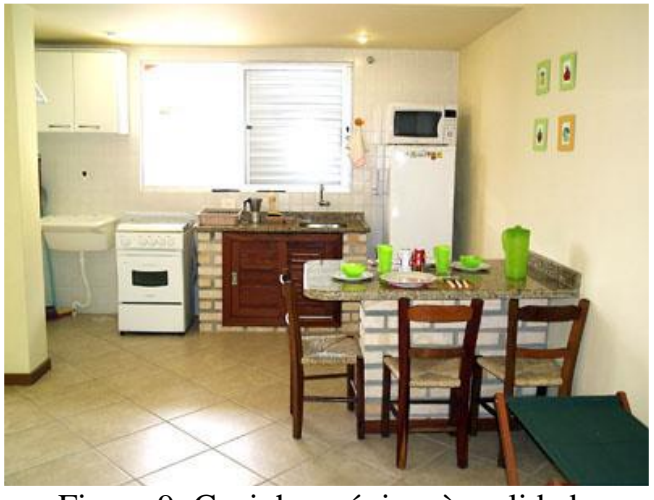

Figura 9: Cozinha próxima à realidade

Fonte:http://www.recantodocampeche.com.br/?modo=d etalhes recanto\&detalhes $=$ cozinha

Mesmo sendo classificada com um ambiente distante da realidade econômica, social e cultural do qual os pesquisados fazem parte, a cozinha [Figura 10], foi apontada como a mais bonita entre os idosos. Alguns deles, destacaram a boa iluminação e o mobiliário como atributos relevantes. $16^{\circ}$ Ergodesign - Congresso Internacional de Ergonomia e Usabilidade de Interfaces Humano Tecnológica: Produto, Informações Ambientes Construídos e Transporte

$16^{\circ}$ USIHC - Congresso Internacional de Ergonomia e Usabilidade de Interfaces Humano Computador

CINAHPA | 2017 - Congresso Internacional de Ambientes Hipermídia para Aprendizagem.

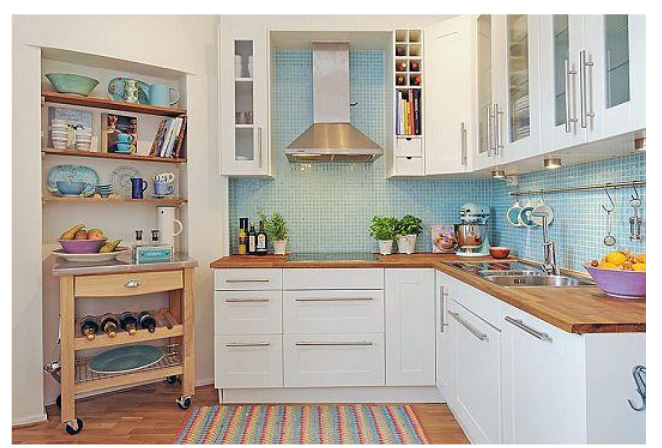

Figura 10: Cozinha considerada mais bonita

Fonte: http://decoratta.com.br/cozinhas-simples/

O ambiente da área de serviço apresentou opiniões divergentes entre os participantes da pesquisa, onde comentários contrastantes foram identificados. $\mathrm{O}$ ambiente qualificado como o mais bonito [Figura 11] recebeu críticas pelo seu amplo dimensionamento, não sendo um aspecto positivo, como pode ser verificado na resposta de um idoso: "Que área de serviço monstruosa é essa? Enorme!".

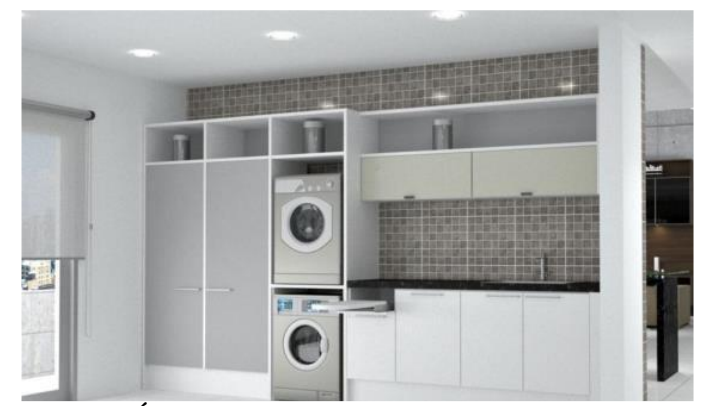

Figura 11: Área de serviço apontada como mais bonita Fonte:http://www.decoracaoplanejada.com/exterior/area -de-servicos-planejada

Mesmo alguns idosos pontuando o amplo dimensionamento como um aspecto negativo, a área de serviço que apresentou maior índice de rejeição [Figura 12] foi classificada como "pequena" e "apertada". A simplicidade que o ambiente demonstrar ter foi pontuado como um ponto negativo. Assim, a área de serviço foi o ambiente que apresentou maior divergência de opiniões. 
$16^{\circ}$ Ergodesign - Congresso Internacional de Ergonomia e Usabilidade de Interfaces Humano Tecnológica: Produto, Informações Ambientes Construídos e Transporte

$16^{\circ}$ USIHC - Congresso Internacional de Ergonomia e Usabilidade de Interfaces Humano Computador

CINAHPA | 2017 - Congresso Internacional de Ambientes Hipermídia para Aprendizagem.

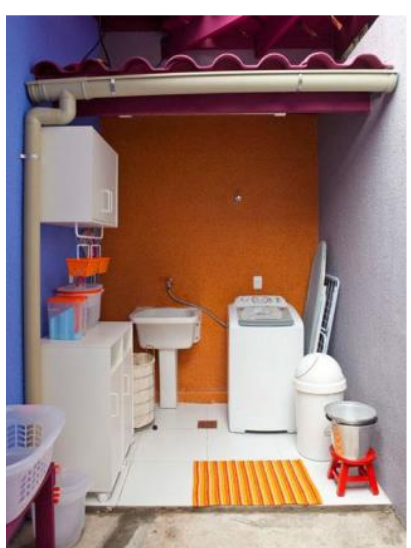

Figura 12: Banheiro mais rejeitado

Fonte: http://construdeia.com/area-de-servico-simples/

Visando identificar se o condomínio em que moram está de acordo com suas necessidades e expectativas, imagens de áreas externas de residenciais similares foram apresentadas aos idosos. Sendo possível verificar se existe identificação desses ambientes com o próprio espaço em que vivem.

Ambientes presentes nas imagens apresentadas e que existem no condomínio em que os idosos residem (academia, por exemplo) foi percebida. Isso gerou reconhecimento por parte dos idosos, onde um deles notou a presença de grama na área da academia e indicou como um aspecto positivo. Porém, mesmo com esses atributos relevantes, a área externa do condomínio escolhido como a mais bonita [Figura 13] foi aquela em que a maioria dos idosos encontraram semelhanças com o próprio residencial.

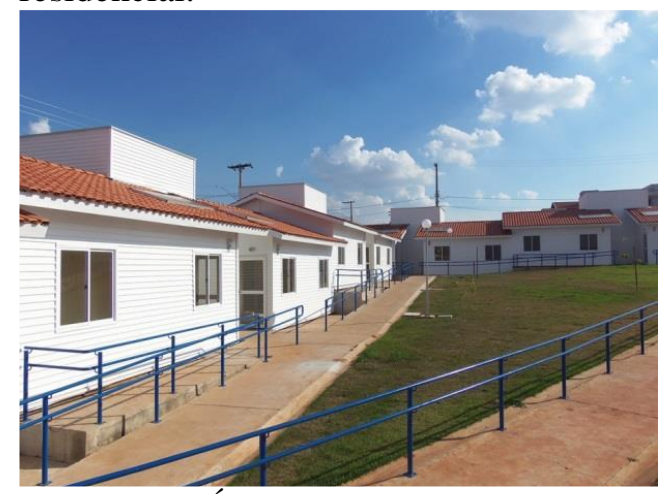

Figura 13: Área externa do condomínio mais bonito Fonte: http://silviotorres.com.br/noticias/governo-doestado-realiza-sonho-da-casa-propria-de-24-idosos-de-

\section{$\underline{\text { mogi-morim/ }}$}

Como mencionado, foi inserido entre as imagens dos condomínios, uma fotografia do residencial Cidade Madura a fim de verificar se os idosos que residem e usufruem desse espaço o identificam. Sendo assim, a maioria dos pesquisados (12 idosos) reconheceram o próprio condomínio, informando que viviam naquele local. Porém, os demais não distinguiram o residencial, como mostra o seguinte comentário: "Eita, essa é linda, né?! É, mas parece com uma daqui”.

Apesar da ferramenta aplicada aos idosos ter conseguido êxito na identificação de atributos em relação aos ambientes, foi registrado um percentual que não realizou comentário algum quando apresentadas as imagens, ou simplesmente usaram de expressões superficiais, com conceitos pouco expressivos como "é bonito" ou "não gostei".

A Seleção Visual provocou o encontro de opiniões antagônicas ou sem clareza entre os idosos participantes, o que dificultou na classificação dos ambientes. Tal fato concorreu negativamente para a conversão dos desejos e anseios identificados em palavras concretas por parte do pesquisador.

\section{Conclusão e Considerações Finais}

A relação do homem com o ambiente faz parte de sua natureza, e acontece por vezes sem que seja percebida. São muitos os aspectos que envolvem essa ligação, sejam socioeconômicos, psicológicos, culturais, técnicos, materiais ou mesmo organizacionais. Desse modo, o entendimento de como o ambiente afeta o usuário e vice-versa é de fundamental importância para a adequação ergonômica dos espaços edificados.

A ferramenta estudada, mesmo utilizando-se de representação através de imagens, não conseguiu detectar com profundidade como os idosos percebem o espaço em que moram, nem o que eles desejam quanto aos ambientes que compõem suas residências. Esse fato foi percebido devido à grande parcela dos pesquisados que não comentaram alguma das imagens ou se
Realização:

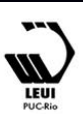


$16^{\circ}$ Ergodesign - Congresso Internacional de Ergonomia e Usabilidade de Interfaces Humano Tecnológica: Produto, Informações Ambientes Construídos e Transporte

$16^{\circ}$ USIHC - Congresso Internacional de Ergonomia e Usabilidade de Interfaces Humano Computador

CINAHPA | 2017 - Congresso Internacional de Ambientes Hipermídia para Aprendizagem.

expressaram de forma superficial, utilizando apenas expressões como "gostei", "não gostei" ou "bonita", sem justificar suas respostas.

A Seleção Visual se mostrou eficaz à medida em que os idosos pesquisados comentaram as imagens apontando atributos positivos ou negativos dos ambientes. Porém, através dos dados, pode-se concluir que a Seleção Visual não é a ferramenta ideal para compreender quais os reais desejos e anseios que esse público tem quanto às suas moradias, nem como eles percebem o ambiente em que estão inseridos.

Através da aplicação dessa ferramenta, pôde-se observar que o idoso tem dificuldade em expressar suas opiniões e desejos. Esse fato pode ser associado ao fator socioeconômico dos pesquisados, visto que esses idosos apresentam certo grau de conformismo com a realidade em que vivem, não apresentando sonhos ou perspectivas de mudanças. Esse aspecto interfere diretamente no modo em que os idosos entendem e enxergam o mundo.

\section{BIBLIOGRAFIA}

DEL RIO, V. Cidade da Mente, Cidade Real: Percepção Ambiental e Revitalização na Área Portuária do RJ. In: DEL RIO, Vicente; OLIVEIRA, Lívia (Orgs). Percepção ambiental: A experiência brasileira, p. 3-22, $2^{\text {a }}$ ed. São Paulo: Studio Nobel, 1999.

GJERDE, M. Visual aesthetic perception and judgement of urban streetscapes. Paper for Building a Better World: CIB World Congress. 2010.

NATHAN, A; WOOD, L; and GILES-CORTI, B. Perceptions of the Built Environment and Associations With Walking Among Retirement Village Residents. In Environment and Behavior, volume 46(1), pages 46-69, 2014.

PAIVA, M. M.; SOBRAL, R.; VILLAROUCO, V. Avaliação estética em ambientes residenciais de idosos, p. 293-303 . In: Anais do VI Encontro

Nacional de Ergonomia do Ambiente

Construído \& VII Seminário Brasileiro de

Acessibilidade Integral. Blucher Design

Proceedings, v.2 n.7. São Paulo: Blucher, 2016.

\section{PARAÍBA. Secretaria de Estado do}

Desenvolvimento Humano. Disponível em: <http://paraiba.pb.gov.br/desenvolvimentohumano/>. Acesso em: 26 jan. 2015.

PINHEIRO, J. Q.; ELALI, G. A.. Comportamento socioespacial humano. In: Temas básicos em Psicologia Ambiental. CAVALCANTE, Sylvia; ELALI, Gleice A. (Orgs). Petrópolis: Editora Vozes, 2011.

SANOFF, H. Community participation methods in design and planning. United States of

American: Wiley, 2000.

\section{SANOFF, H. School Building Assessment}

Methods. AIA, Celen Pasalar, and Mine Hashas, School of Architecture, College of Design, North Carolina State University with support from the National Clearinghouse for Educational Facilities, 2001. Disponível em: <

http://www4.ncsu.edu/unity/users/s/sanoff/www/sc hooldesign/schoolassess.pdf $>$. Acesso em: 25 jun. 2015.

SOBRAL, Elzani.; PAIVA, Marie;

VILLAROUCO, Vilma. Ambiente de idosos e a

ferramenta Poema dos Desejos. In: $16^{\circ}$ Encontro Nacional de Tecnologia do Ambiente Construído, 2016, São Paulo. Anais... Porto Alegre: ANTAC, 2016.

VERONESI, Jr. J.R. Fisioterapia do trabalho: cuidando da saúde funcional do trabalhador. São Paulo: Andreoli, 2008.

VILLAROUCO, V.; ANDRETO, L. Avaliando desempenho de espaços de trabalho sob o enfoque da Ergonomia do ambiente construído. Revista Produção, Vol.18, n.03, set/dez 2008, ISSN 0103-6513. São Paulo: ABEPRO, 2008.
Realização:

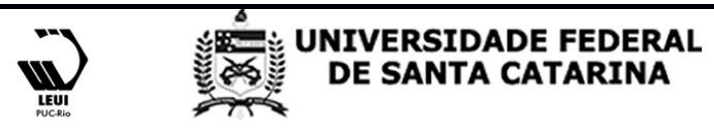

